\title{
Cultural Integration of Inter-State Migrants in Asansol, West Bengal
}

Mukesh Singh $^{+*}$ and Professor Giyasuddin Siddique ${ }^{¥}$

\section{Abstract}

Migration brings about changes in the cultural traits of both migrants and the receiving society. This becomes even more crucial, especially for India, which is characterised by rich cultural diversity and substantial inter-state migration. Cultural integration is the strategy of cultural exchange wherein one community incorporates changes without sacrificing its own culture, and thus, pave the way for a more stable and harmonious society. Migration in Asansol dates back to early 19th Century when the newly set up coal mining and the subsequent industrial development generated the demand for labour. Migrants brought with them a distinct culture which had to be reconstructed in the new cultural setup. This study is an attempt to understand the phenomena of cultural and psychological integration of the migrants in Asansol. A descriptive method has been employed to comprehend the migrants' adaptation and the consequent socio-cultural changes. A sample of $\mathbf{3 7 0}$ individuals has been taken to explore the migrant's outlook toward integration with the larger society. Emphasis has been laid upon the way the migrants reconstruct themselves, appraise their perception and adopt the dominant cultural traits. The study reveals that the migrants have immensely influenced the culture of the region under investigation.

Keywords: Culture; Cultural Integration; Cultural Change; Inter-state Migrants; Migration; West Bengal; India

\footnotetext{
${ }^{\dagger}$ Junior Research Fellow (PhD Scholar), Department of Geography, The University of Burdwan, Burdwan, West Bengal, India

${ }^{*}$ Corresponding Author, Email: mukesh01041993@gmail.com

¥ Department of Geography, The University of Burdwan, Burdwan, West Bengal, India

(C) 2020 Singh \&Siddique. This is an Open Access article distributed under the terms of the Creative Commons Attribution License (http://creativecommons.org/licenses/by/2.0), which permits unrestricted use, distribution, and reproduction in any medium, provided the original work is properly cited.
} 


\section{Introduction}

Migration of people across geographical space does not only modify the population dynamics of the region concerned, instead, it is associated with socio-economic repercussions (Gibson, 2001; Berry, 2001). The reasons for migration from any region are social insecurity, political unrest, religious oppression, ethnic conflicts, economic aspirations, etc (de Haan, 1995; Gibson, 2001). Among these, the migration for economical purpose is the dominant pull factor (de Haan, 1995). When migrants settle in a new cultural environment, a process of cultural change is the apparent outcome (Scheffler, 2007). It results in the exchange of cultural traits with the host culture.

The antecedent of migration flow to Asansol can be traced to the demand for labour in the mines and industries during the 19th and 20th Centuries. Majority of them were from the states of Bihar and Uttar Pradesh (Peterson, 1910; Mukhopadhyay, 1998). With the course of time, the migrants have become the majority in the cultural landscape of Asansol. As per the Census of India (2001), Bengali speaking people are around $45 \%$ of the total population. The present study aims to understand the continuation, adaptability and changes of cultural traits among the migrants in the area under study. An attempt has been made to recognise the strategies of cultural integration which has led to the present cultural mosaic of Asansol.

The study begins with an introduction outlining the nature and importance of studying cultural integration of migrants in Asansol. It is followed by a literature review highlighting the different theories and concepts of migration, cultural changes and cultural integration. A short description of the study area is given, followed by the methodology of the study. A detailed account of the inter-state migration in Asansol considering the historical context has been outlined. This is followed by a study of the cultural practices of the migrants in the region. The approaches of cultural integration have then been discussed, and finally, a conclusion has been drawn.

\section{Literature Review}

Migration is the process of shifting of the population over geographical space. Based on the movement of people across the national boundary, it is viewed as either internal migration or international migration (Chandna, 2001). Inter-state migration is one component of internal migration wherein migrants moves across the state boundaries within a nation. The volume of inter-state migration is far more than the international migration even then it has not received that much attention among the researchers (Bhagat, 2016). Migration studies in the recent times have focused primarily on the racial and ethnic conflicts, psychological impediments in incorporating changes and acceptance of migrants by the host communities (Sanchez, 1995; Phinney et al., 2001). The major thrust of the studies on the cultural aspects of migration lies in the migrants' attitude toward acculturation in the Western nations, primarily the United States (Farver et al., 2002).

Culture is viewed as a collective whole comprising values, norms, customs and behaviour of an individual or a society (Berry \& Sam, 2016). It encompasses not only the art, music, literature, architecture of the society but also a variety of other things such as food, dresscode, cuisine, and so on (Carlson \& Guler, 2018). The identity and behaviour of an individual to a large extent, is shaped by the cultural landscape of the area concerned (Bhugra \& Becker, 2005). Thus, the culture is a complex of various attributes which helps to understand society as a whole. The cultural cost of migration requires even more importance in a country like India, which is characterised by a freedom of interstate migration granted by its Constitution and the vast cultural diversity (Bhagat, 2016). The necessity of interaction with the host culture compels the migrants to adapt to the prevailing cultural setup. Hence, the changes in the customs, economic and political life is observed not only among the migrants but also the host population. This change is never simple; rather, 
it can be stressful and results in the problem with self-esteem and mental health (Berry, 2001; Bhugra \& Becker, 2005). It brings about significant changes in the psychology of the individual (Sayegh \& Lasry, 1993; Phinney et al., 2001). The psychological well-being of the migrants is immensely influenced by their attachment to the culture of origin.

Berry \& Sam (2016) has illustrated the changes encountered by immigrants both at the group level and at the individual level. At the group level, the changes are reciprocal, wherein both migrants and host cultures experience changes. However, at the individual level, individuals undergo psychological changes that is, changes in behaviour, attitude, and values. Migrants try to adapt to the local culture by incorporating changes in their socio-cultural conducts (Berry, 1997; Phinney et al., 2001).

When migrant settles in an area whose prevailing culture is different from that of migrants, a process of cultural exchange is observed, which is known as acculturation (Berry, 1997; Scheffler, 2007). Acculturation is the process of cultural change and adaptation that occurs when individuals from different cultures come in contact with each other (Gibon, 2001). It then becomes prerequisite to know which cultures are coming in contact to understand the level of acculturation. Because, the closer the cultural traits are, the smoother the acculturation process is and vice-versa (Carlson \& Guler, 2018). Berry (2001) has suggested a framework to study the psychology of cross-cultural migrants, which comprises four, processes that is, assimilation, integration, isolation and marginalisation. Assimilation occurs when there is less or no interest among the migrants to maintain their original culture and preference is given to the acceptance of the culture of the host society in its entirety (Carlson \& Guler, 2018). Separation is the way when cultural maintenance is sought while avoiding involvement with the host. Marginalisation happens when neither cultural maintenance nor interaction with the host is observed (Berry et al. 2006). Rejection is an exclusionary process wherein the migrants are restricted to interact with the host. This is common when migrants are illegal, less proficient in adaptability, and finally ends up in ghettos, leading a distressful life. The process of cultural integration is more liberal in outlook wherein both the cultural groups co-exist and maintain their original cultures and at the same time, accept the cultural traits of each other (Scheffler, 2007).

Cultural integration refers to the coexistence of different cultures in a single area (Bhugra \& Becker, 2005). Integration is achieved on three levels that is, socio-economic, cultural and political (Gupta, 2017). Socio-economic integration comprises education, inter-cultural marriage, employment and others. At cultural level integration is achieved through language proficiency, acceptance of values of local culture etc. It starts with perceiving local culture, building social position and achieving social relations to form a sense of belongingness in the host culture. Sense of belongingness of migrants depends on the efficiency of migrants to learn new cultural values, economic needs and the duration of stay in the host culture (Gupta, 2017). It also demands a liberal attitude and friendly outlook from the host society as well. The host society has to open the social institutions and grant equal status to the migrants so as the greater integration of migrants is ensured (Carlson \& Guler, 2018). Integration of migrants does neither involve the forced imposition of cultural belief nor to renounce culture of their origin. Rather it entails the minor cultural changes to incorporate communities which eventually lead towards multiculturalism. Multiculturalism, however, is a broader concept often viewed as the existence, acceptance and promotion of multiple cultural tradition in a single area often equated with a 'salad bowl' (Farver et al., 2002). Cultural integration thus, reinforces the intercommunity interactions and mutual harmony. However, the central thrust of integration always lies on the migrants themselves, not on the host society. However, it is also equally crucial that migrant communities must not do away with the culture of their source area because it gives them psychological stability 
(Sayegh \& Lasry, 1993; Sanchez, 1995). The following section discusses the study area.

\section{The Study Area}

Asansol is the second most populous city in West Bengal (AMC, 2019) and, the 39th largest city in India. It is situated in the westernmost part of Paschim Bardhaman District of West Bengal (Figure 1). Coal mining and the industries are the backbone of the economy of the region. Geographically the region lies in the fringe zone of the Chhotanagpur Plateau. Asansol got its name from the 'Asan' (Terminalia elliptica) and 'Sal' (Shorea robusta) trees found profusely in the region (Peterson, 1910; Sengupta, 1998). The river Damodar bounds it in the south and river Brakar in the west. The Jharkhand State lies in the west, while Bankura district of West Bengal lies in the southern part. The total population of the delineated region was 12,43,414 persons in 2011 (Census of India, 2011).

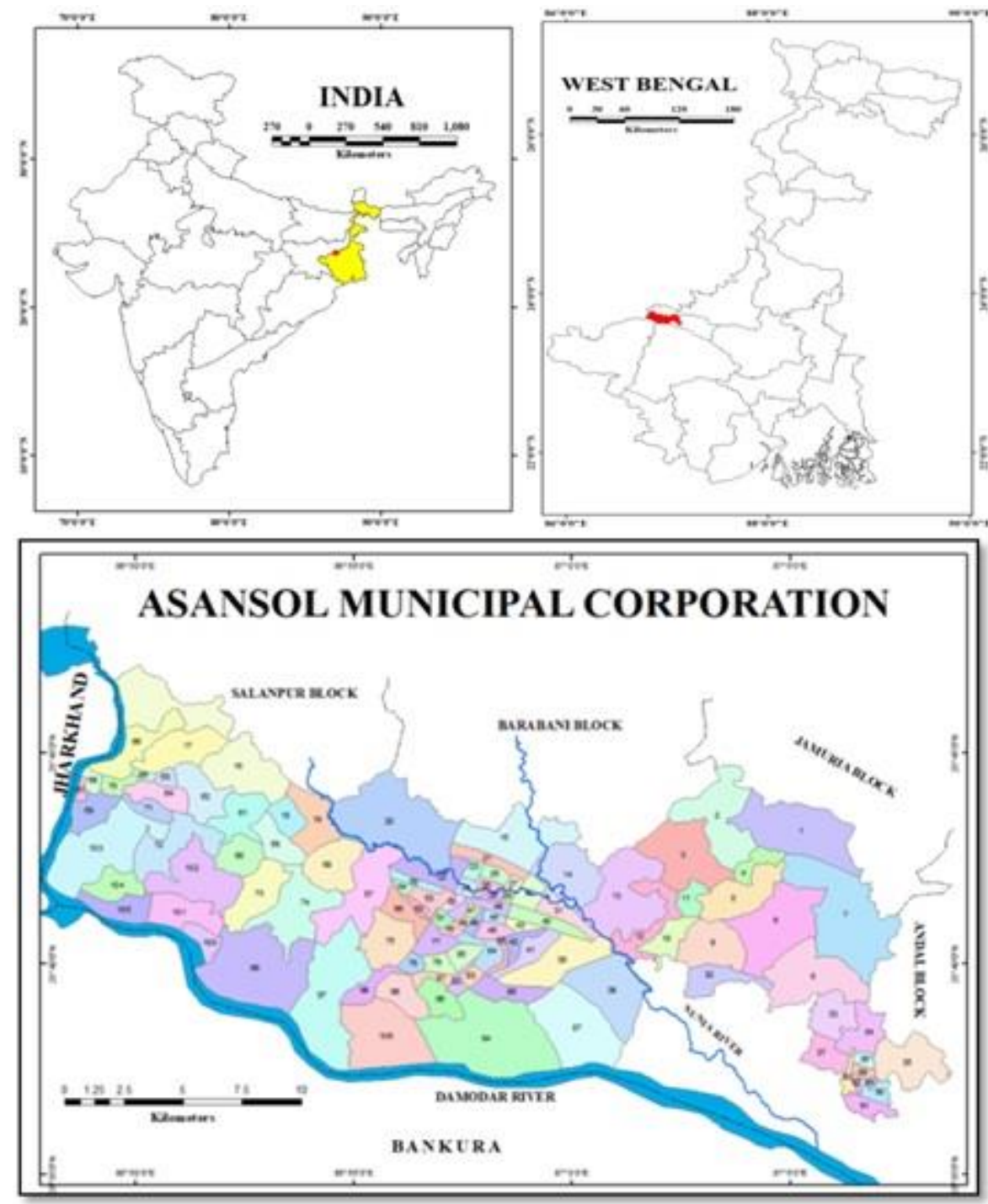

Figure 1: Location of the Asansol Municipal Corporation, 2020 Source: Prepared by the Authors

\section{Database and Methodology}

The present work is an outcome of extensive field study based on structured questionnaire schedules distributed to 400 migrant households; however, 30 questionnaires were found to be inadequate. Therefore, the final study was conducted among 370 migrant households. The households were accessed through a snowball sampling technique wherein the respondents help the interviewer by introducing the next respondents based on their acquaintance. The authors approached the 
respondents with a questionnaire compiled in the English language, which was administered by the first author. The questions were conducted primarily in Hindi; however, in few cases, the language of origin of the migrants such as Bhojpuri, Maithili or Awadhi was also used as the author is competent in these languages. The average age of the respondents was 42.6 years, while the crude literacy rate was found to be $69.09 \%$. Emphasis was laid on the empirical observation of the cultural phenomena. The questionnaires consisted of standard demographic attributes, food habits, language attainment, dress-code, social customs and festivals. Moreover, 12 focus group discussions comprising of 4 to 7 persons in each group were also conducted. Secondary data from Census Handbooks of India 2001 and 2011 and other information from various reports, journals have also been used in this study.

\section{Inter-State Migrants in Asansol: A Journey through History}

The region was densely forested in the preColonial period, and the population was very sparsely distributed. Commercial production of coal in the area was started in Raniganj in the year 1774 (Peterson, 1910). Development of iron and steel and other auxiliary industries in the region bestowed additional momentum to the mining activities. Coal mining activity attained a new fillip with the introduction of railways in 1855 . The apathy of the local residents to work in the coal mines made the migrants opportune to get employed at ease. The reasons for less involvement of locals in mining and industrial activities were a) they were the first eyewitness to the oppression of the owners, $b$ ) the salary in mining jobs was very low and c) agriculture then proved no less beneficial than working in mines (Sengupta, 1998). Moreover, migrants were also employed as darwarns (guards) and ardalis (peons) by the landlords. The Marwari community (migrants from Marwar of Rajasthan), got hold on the economic space developed as a result of the growth of trade and commerce (Peterson, 1910). At the onset of the previous Century, Burdwan district received the highest number of inter-state migrants than any other districts of the province. The eastern part Uttar Pradesh, western Bihar and eastern Madhya Pradesh have been the source areas of migration to the urban centres of Bengal during the significant parts of the 19th and 20th Century (Mukhopadhyay, 1998).

The participation of migrants in economic space of Asansol can be understood by the fact that about $70 \%$ of the workers in the mines of Raniganj coalfield had been from other states of India (Mukhopadhyay, 1998). The migrant workers from Bihar constituted the majority among all the migrants. Interestingly, with due course of time, this migrant folk has become the majority in the cultural landscape of the region. According to an estimate of research in 1979, the migrants from the other states formed the majority of the worker. Migrants from Bihar constituted about 23\%, while those from Uttar Pradesh and Madhya Pradesh, constituted about $19 \%$ and $16 \%$ of total migration respectively (Sengupta, 1998).

As per Census of India (1991), out of the total population of 220949, the Bengali speaker constituted 99689 (45.12\%) while 91748 (41.52\%) were Hindi speakers. A study in the early 1990s reveals that out of 30 wards of the Asansol Municipal Corporation, 13 had Bengali majority, 12 had non-Bengali majority while 5 had an equal ratio of the both (Sengupta, 1998). The Census of India (2011) shows that the nonBengalis are the majority in the region. About $55 \%$ of the total population speaks either Hindi or Urdu. Migrants from Bihar (52.93\%) constitute a significant portion of the total migrants. While those from Jharkhand and Uttar Pradesh, constitute $25.63 \%$ and $13.68 \%$ respectively (Figure 2). Moreover, migrants from Punjab and Rajasthan also have a significant presence.

The majority of the migrants (62\%) in Asansol have come from the states of North India like Bihar, Uttar Pradesh, Jharkhand, in search of better economic opportunities. Out of them, $8.88 \%$ came here for government jobs, while the rest $(53.45 \%)$ to get employed in different occupations. The second most prominent 
reason for migration in Asansol is to escape from environmental hazards (16.31\%) in their source areas (Figure 3). Uttar Pradesh and Bihar are situated in the Gangetic Plain; recurrent flood hazards had been a major compelling factor for the migrants to leave those regions. Besides, western Bihar and eastern Uttar Pradesh experienced severe drought conditions for a long period (Dallmann \& Millock, 2017; de Haan, 1995; Mehta, 1991).

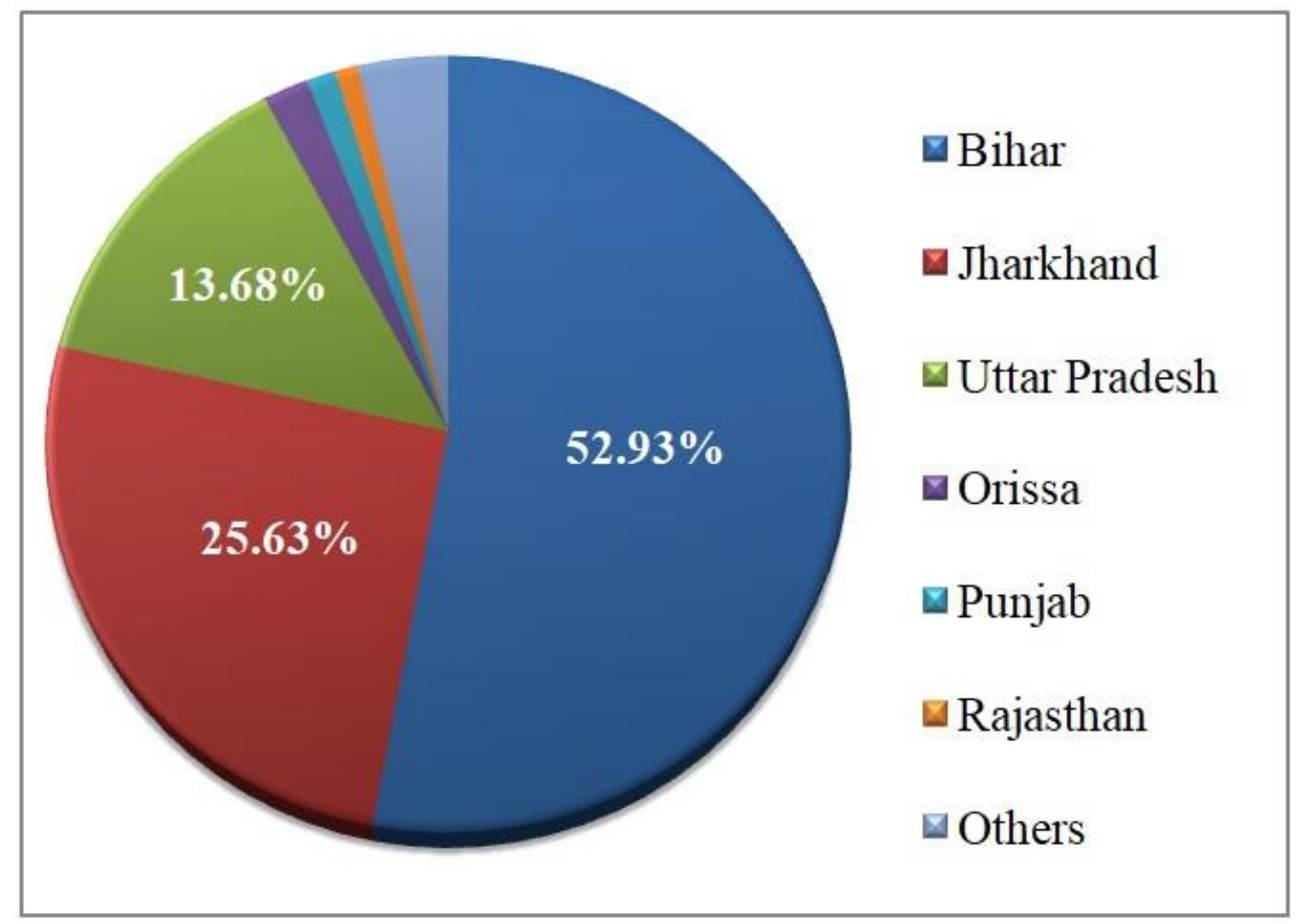

Figure 2: Source States of Migrants

Source: Census of India, $2001^{1}$

\footnotetext{
${ }^{1}$ The corresponding data for the 2011 census is not yet released hence we had to rely on the 2001 data.
} 


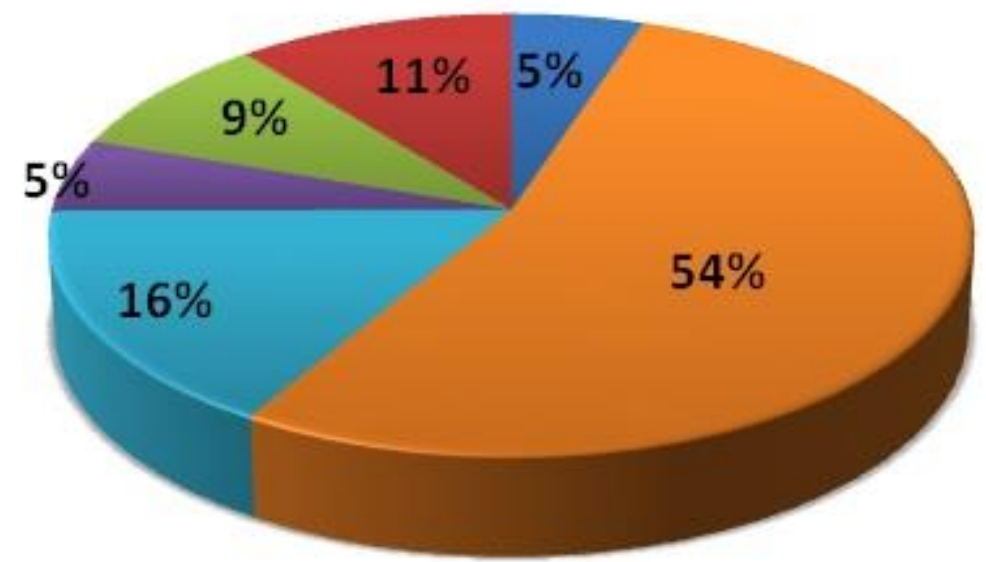

Schooling for children $\quad \square$ For Work

$\square$ Escape environmental hazards $\square$ Family conflict

$\square$ Government Service

$\square$ Others

Figure 3: Reason for Migration in Asansol

Source: Field Survey, 2019

\section{Understanding the Culture of Inter-State Migrants in Asansol}

The cultural practices among the migrants in the region are the outcome of the acceptance as well as the rejection of some cultural traits of both the cultures manifested through prevalent food, dress, rituals, etc.

- Food: Food is the most significant cultural sign which makes up the identity of the people and their sense of otherness (Gupta, 2017). The migrants strive to maintain their unique dietary behaviour because it is something which is attached to them since their birth (Najia et al., 1986). In the study area, the migrants have undergone significant changes in their food habits. The survey results of the research unravel that the food habits of $60.3 \%$ of the total migrants are non-vegetarian, and $39.7 \%$ are vegetarian. Changes in food habits can be understood by the fact that $22.7 \%$ of the migrants have shifted their vegetarian habit to non-vegetarian. In comparison, $35.9 \%$ of them have retained their vegetarian tradition. Similarly, $37.6 \%$ of the non-vegetarians have retained their food habits, whereas $3.8 \%$ of the migrants have changed their dietary choice from non-vegetarian to vegetarian. Only about $20 \%$ of the youth migrants prefer food of their source area. However, the older generation is strict about changing their food habit. About $40 \%$ of the older migrants prefer food of their source area. One common feature among both the generation of migrants is that they are very little interested in the local Bengali food.

- Dress: The sense of distinctiveness in dress material is the indication of the personal and public way of the identity of an individual. It not only protects the modesty but also signifies the cultural trait associated with them (Mehta, 1991; Scheffler, 2007). Often communities make it mandatory to wear their traditional dress on certain festive occasions to assert their conceited history (Sayegh \& Lasry, 1993). 
However, there is remarkable variation in the preservation of traditional dress code across age groups as it is symbolic in portraying the individual's identity in the society. The factors that influence the preference of dress code of migrants are a distance from the core of the city, time spent in the destination area, age of the migrants, nature of the occupation of the migrants and others. People at the core of the city tend to shift toward modern dresses whereas those living in the outskirts of the city have a propensity to maintain their dress code of the source area (Scheffler, 2007). The findings reveal that only $2.6 \%$ of the male and $4.92 \%$ of the female migrants wear their traditional dress on a daily basis. $21.69 \%$ of male and $46.36 \%$ of the female migrants wear traditional attire during festivals while the rest have shifted to modern dresses. Hence, the festival is one of the essential occasions when to assert the culture through dress code. Generally, women are the flag bearer of the culture of a community. Thus, the traditional wear of the migrants has become purely ceremonial and auspicious in nature.

- Rituals: 'Ritual' is defined as the way of organising certain occasions. It is generally age-old préserved order of conducting specific event like birth, death, marriage etc. On average, $64.65 \%$ of the female and $54.63 \%$ of the male migrants visit the place of their worship during some kind of festivals. Only 5.31\% of the female and $1.86 \%$ of the male migrants visit their place of worship daily. Females are more frequent visitors, while the children are the least to the place of worship.

The migrants in Asansol city area show a mixed approach in maintaining their traditions. However, their tendency to acquire the local tradition is very meagre. New generation migrants show significantly less interest in practising their traditional customs. Almost 52.81\% of the migrants prefer a mixed manner which is influenced by the local as well as the popular way of organising birth ceremonies. In contrast, about $10.28 \%$ of the migrants have adopted the local way. Almost $36.91 \%$ follow the traditional way. Marriage is a significant event so far as the cultural practices of the migrants are concerned. Adoption of local elements is significantly less in case of marriage rituals, $51.42 \%$ of the migrants follow their traditional way of marriage. Those accepting the local rituals constitute $14.35 \%$ of the total migrants, whereas $34.23 \%$ of the migrants follow the mixed way. The acceptance of local rituals is more possible in inter-cultural marriages. Migrants have retained their original way of observing the death rites. $68.7 \%$ of the migrants follow their traditional rituals. Only $7.03 \%$ of the migrants have accepted the local rituals and the rest $(24.27 \%)$ follow the mixed way of conducting the rites (Figures 4).

- Language: Language is the first step in the participation of migrants in the receiving area. The attainment of local language determines the degree of acculturation of the migrants (Berry, 1997; Farver et al., 2002). Weakness in acquiring local language hampers migrants the access of social, economic and political environment of the destination area.

The research survey unfolded that more than half of the population of the region (54.11\%) is non-Bengali. Besides Bengali, Hindi is the second most spoken language (30.33\%), followed by Urdu (18.04\%). The majority of the migrants are conversant in more than two languages (56\%). The languages spoken by migrants at home are Bhojpuri (29.1\%), Magadhi (18.4\%), Maithili (18.4\%). $14 \%$ of them can communicate in more than three languages. However, a small proportion of migrants (8\%) can communicate only in one language, which is the language of their source 
area. The languages spoken by the migrants at the workplace and home are often different. Hindi is the language of everyday activities (69.5\%), but the migrants use the language of their source area at home (56.6\%). At workplaces, Bengali, the official language of the State, is spoken by $25.7 \%$ of the migrants. Migrants have to get acquainted with Bengali to get access to the social and economic space. About $64 \%$ of migrants believe that it is necessary to learn Bengali. Interestingly, the learning of language is not unidirectional; instead, locals imbibe the migrants' language too. It thus ensures the harmonious social ambience favourable to the migrants.

- Occupation: Migrants are engaged in varieties of jobs as a government employee, workers in the unorganised sectors, businesses and others.
Nevertheless, many of them lack a skill that compels them to opt for underpaid strenuous jobs as a rickshaw puller, roadside-vendors, daily labour and similar low skilled job. The findings of the survey revealed that about $45 \%$ of the migrants are associated with business activities. $23.11 \%$ of the migrants are engaged in salaried jobs, while $17.45 \%$ performs professional activities. Several factors are responsible for the choice of changes in migrants' occupation. The skill of the individuals, their educational attainment, and technological exposure determine their adoption of occupation. The caste identity of an individual has a great bearing in preferring occupation, especially when there is a shift in occupation base (Chandrasekhar \& Mitra, 2019).

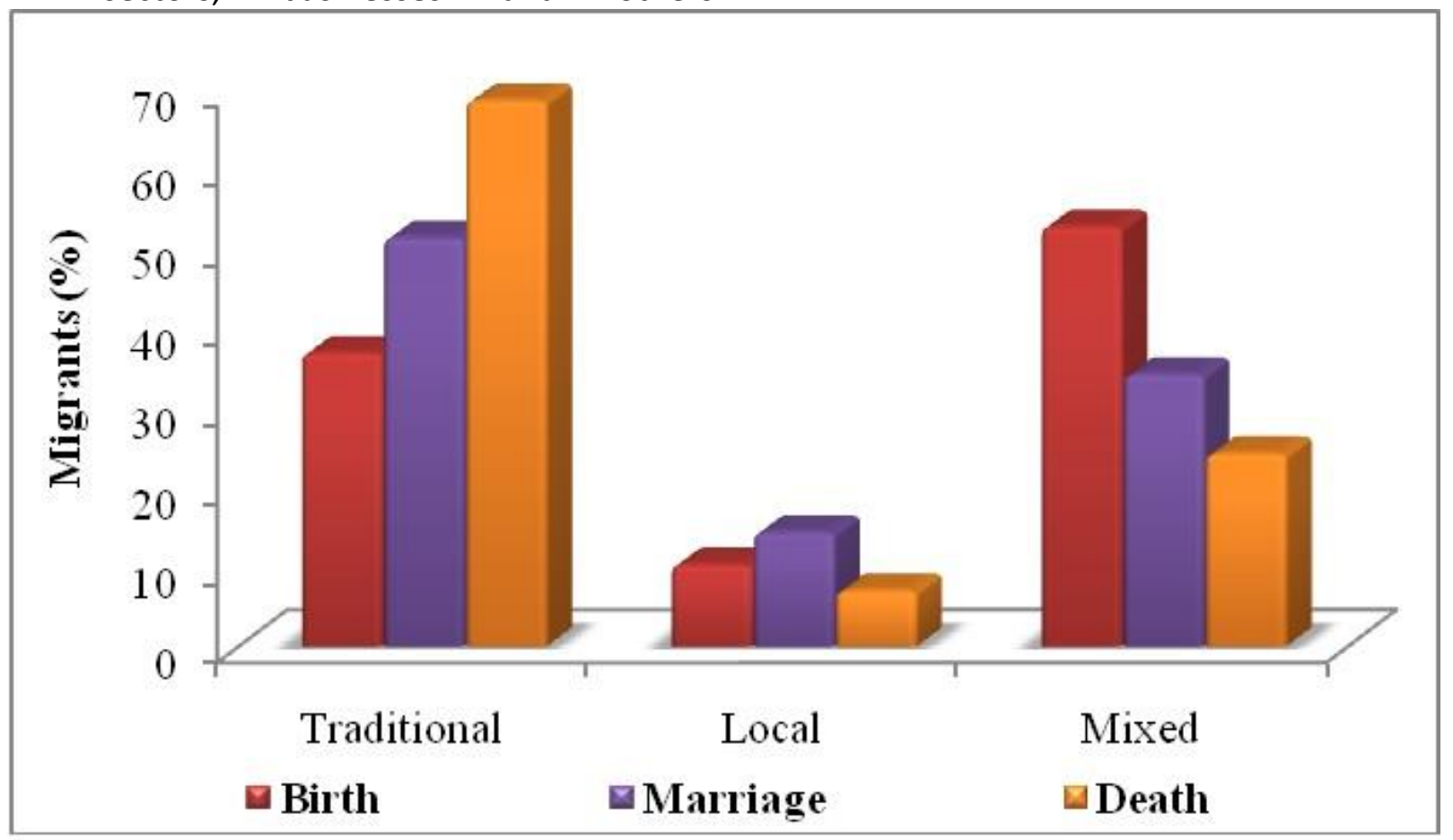

Figure 4: Way of Observing Rituals

Source: Field Survey, 2019

The Strategies of Cultural Integration and Formation of Cultural Identity

Several factors are responsible for the integration of migrants in the host society viz. language proficiency, intercultural marriage, sense of belongingness and residential segregation.

- Inter-Cultural Marriage: It results when there is a close cultural exchange. Ethnic exclusivity of the migrants has mostly shattered away when there are more 
inter-cultural marriages. There are two variants of opinion regarding the role of inter-cultural marriage in integration. The first group of opinion views the inter-cultural marriage as the result of the integration process, whereas the second group of opinion believes this as the driving force of the social interactions (Carlson \& Guler, 2018). About $89.53 \%$ of the target groups of the study area prefer marrying strictly within the community. Very meagre proportion (4.31\%) of the migrants is in favour of inter-community marriage. Migrants prefer to organise marriage in the locality of the destination area rather than at their place of origin. Nearly $19.47 \%$ of the migrants move to their place of origin to organise marriage ceremony.

- Sense of Belongingness: Sense of belongingness of the migrants implies as to how they perceive the area they have settled in. It depends on the length of stay in the host culture; the efficiency of migrants to learn new cultural traits and the relative economic importance of learning it. The composition of the neighbourhood, frequency of visit to the place of origin, maintaining contacts with the communities of their origin are some of the other factors which determine the sense of belongingness of the migrants in the host culture (Phinney et al., 2001). $49.18 \%$ of the migrants in the area under review consider themselves to be identified with their source region. A very meagre proportion $(9.38 \%)$ of the migrants recognise themselves as Bengali as local identity. Thus, the migrants have a strong affiliation with their source-region in terms of their identity.

- Language: The migrants' outlook toward the necessity of learning the local language can be understood by the medium of schooling of their children (Scheffler, 2007). The research findings reveal that about $50 \%$ of the migrants' children study in Hindi medium schools. English is the second most preferred medium of schooling. Only about $5 \%$ of the migrants' children attend Bengali medium schools. This clears that there is no dearth of Hindi medium schools, and hence they are free to choose the medium of schooling of their children (Figure 5).

- Residential Segregation: Residential segregation may be defined as the extent to which two communities are living separately in an area (Sayegh \& Lasry, 1993). There are numerous such pockets developed in the region like Koiri Mahalla, Mungeri Basti, Gaya Mahalla, Balia Basti, Goala Para, etc. (Mukhopadhyay, 1998). The reasons are: easy access to the social sphere, access to the place of worship etc. More important is the sense of security. However, this is a negative sign of cultural integration with the dominant society. It restricts the social cohesion of the migrants with the receiving society. $49.62 \%$ of the migrants are settled in an area where the majority of the people are from their community. About $32.47 \%$ are living in an area composed of a fusion of different communities while only $17.91 \%$ of the migrants are living in areas dominated by the local community.

- Role of Government and NonGovernmental Organisations: The government, as well as the nongovernment organisations, always play a crucial role in encouraging the intercultural harmony. Numerous such organisations are working for that cause in the region as well. Marwari Yuva Munch is one such organisation which strives for the social welfare of every community. Philanthropist works by the Sikh organisations cannot be overlooked. Further, at the local level, different clubs, cultural groups organise various religious and cultural functions. Asansol Hindi Academy is working diligently in this regard. It works under Asansol Municipal 
Corporation. Cultural functions, seminars are organised primarily among the migrant communities. It works for the growth of Hindi language in Asansol.

- Political Representation of the Migrants: The Hindi-Bhasis (Hindi speakers) is the core of political affairs in the region. Not only in Asansol, but for the entire Paschim Bardhaman district, the Hindi speakers have a crucial role to play in the different level of the political hierarchy. However, the fact is that these people themselves are not much involved in political activities. Illiteracy, cultural isolation etc. are seen as the major impediments for less participation in political conducts. Nonetheless, their participation is gradually increasing with increasing political awareness. There are a significant number of elected representatives from the migrant communities as Councillors in the Asansol Municipal Corporation (AMC, 2019).

Several attempts are being made to gain the confidence of these communities, such as special arrangements of Chhath Ghats (a place to worship goddess Chhath). State holiday for two days was declared during Chhath Puja (a very popular festival of worshipping sun among the migrants). Besides, there was a proposal to build Sun temples in some places to lure the Hindi speaking people, especially the Bihari (People of Bihar State) voters (Chatterjee, 2018).

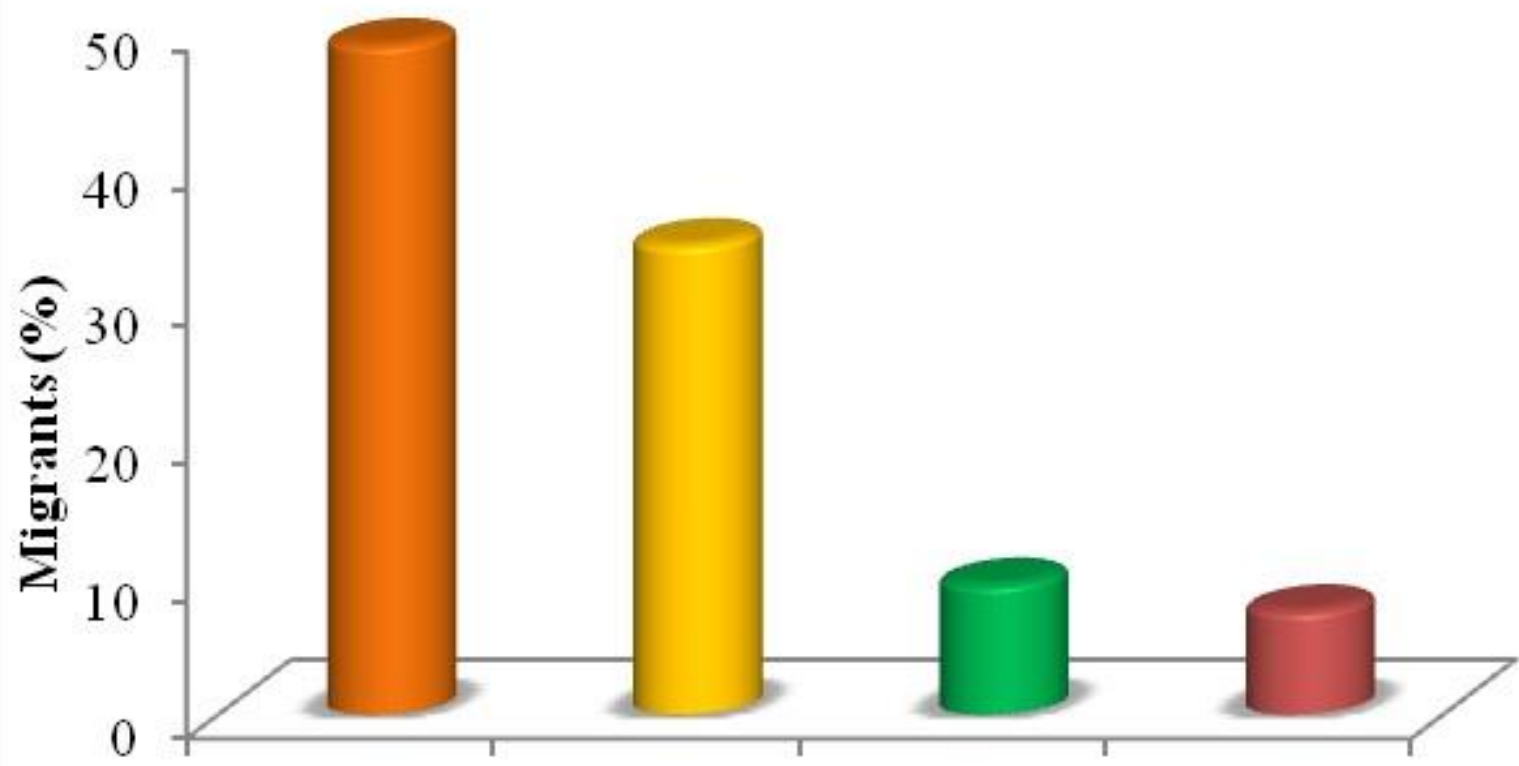

Hindi English Urdu Bengali

Medium of Schooling

Figure 5: Medium of Schooling of Migrants' Children

Source: Field Survey, 2019

\section{Factors of Cultural Integration}

- Learning local language: Migrants learn a local language which not merely expands their contact with the local population but also ensures them access as well to the administrative types of machinery (Gupta, 2017). It also supplements the migrants' friend sphere, participation in local festivals, 
cultural functions etc. and hence their greater integration with the local society.

- Mutual respect for cultural values: Cultural values are deeply embedded in the individual's personal belief system, which is reflected through his behaviour and outlook (Gibson, 2001). Therefore, both the local as well as migrant communities, need to show respect to the cultural codes and conducts of each other.

- Flexibility in incorporating changes: The cultural rigidity of any sort is always detrimental to cultural integration. Cultural rigidity leads to cultural separation, which widens the gap between cultures (Mehta, 1991).

- Educational opportunities: The welleducated migrants are easily accepted to the host society as they are ready to accept the local culture easily. Hence, educating migrants' children strengthen their acceptance and thereby the social harmony (Gupta, 2017).

\section{Conclusion}

Inter-state migration has proved to be a boon for both the economy of the region and the migrants. The economy has been benefited with human power while in turn, the migrants received their remittances and improved economic status. The present cultural mosaic of Asansol is the outcome of the intermixing of the cultures which have given it a multicultural character. It thus resembles the concept of cultural integration wherein; the different cultures have given to and taken from each other, at the same time, maintaining their distinctive cultural peculiarities. The local community has also been accommodating the migrants' cultural traits in theirs. Thus, with participation in the local culture and traditions, the migrants integrate themselves with the host society very efficiently.

\section{References}

AMC (2019). Asansol Municipal Corporation. http://www.asansolmunicipalcorporation.com/ aboutus $/ 1$
Berry, J., \& Sam, D. (2016). Theoretical perspectives. The Cambridge Handbook of Acculturation Psychology, 11-29. https://doi.org/10.1017/CBO9781316219218.0 03

Berry, J.W. (1997). Immigration, acculturation and adaptation. International Association of Applied Psychology, 46(1), 5-34. https://doi.org/10.1111/j.14640597.1997.tb01087.x

Berry, J.W. (2001). A psychology of immigration. Journal of Social Issues, 57, 615-631.

https://doi.org/10.1111/0022-4537.00231

Berry, J.W., Phinney, J.S., Sam, D.L., \& Vedder, P. (2006). Immigrant youth: Acculturation identity and adaptation. International Association of Applied Psychology, 55(3), 303332. https://doi.org/10.1111/j.14640597.2006.00256.x

Bhagat, R.B. (2016). Changing pattern of internal migration in India. In Guilmoto C., \& Jones, G. (Ed.), Contemporary Demographic Transformations in China, India and Indonesia. Demographic Transformation and SocioEconomic Development, vol 5. Springer, Cham. https://doi.org/10.1007/978-3-319-24783-0_15

Bhugra, D., \& Becker, M.A. (2005). Migration, cultural bereavement and cultural identity. World Psychiastry, 4(1): 18-24.

https://www.ncbi.nlm.nih.gov/pmc/articles/PM C1414713/

Carlson, E., \& Guler, A. (2018). Cultural involvement and preference in immigrant acculturation. International Migration and Integration, 19, 625-647. https://doi.org/10.1007/s12134-018-0554-4

Census of India (1991). West Bengal, Migration

Tables. India: Government of India Publications. Census of India (2001). West Bengal, Migration Tables. India: Government of India Publications. Census of India (2011). West Bengal, Migration Tables. India: Government of India Publications 
Chandna, R.C. (2001). Geography of Population: Concepts Determinants and Patterns. Kalyani Publishers.

Chandrasekhar, S., \& Mitra, A. (2019).

Migration, caste and livelihood: evidence from Indian city-slums. Urban Research \& Practice, 12(2), 156-172.

https://doi.org/10.1080/17535069.2018.14267 81

Chatterjee, A. (2018, November 14). Temple spree in West Bengal's Hindi belt. The

Telegraph.

https://www.telegraphindia.com/westbengal/temple-spree-in-west-bengal-s-hindibelt/cid/1675292

Dallmann, I., \& Millock, K. (2017). Climate variability and inter-state migration in India. CESifo Economic Studies, 63(4), 560-594. https://doi.org/10.1093/cesifo/ifx014

de Haan, A. (1995). Migration in eastern India: A segmented labour market. The Indian Economic and Social History Review, 32(1), 51-93.

https://doi.org/10.1177/001946469503200103

Farver, J.A., Narang, S.K., \& Bhadha, B.R. (2002). East meets west: Ethnic identity, acculturation, and conflict in Asian Indian families. Journal of Family Psychology, 16(3), 338-350.

https://doi.org/10.1037//0893-3200.16.3.338

Gibson, M.A. (2001). Immigrant adaptation and pattern of acculturation. Human Development, 44, 19-23. https://doi.org/10.1159/000057037

Gupta, P. (2017). Migration from West Bengal to national capital territory of Delhi: $A$ geographical study (Doctoral Thesis, Punjab University, Punjab, India). http://hdl.handle.net/10603/205977

Mehta, G.S. (1991). Socio-economic aspects of migration. Deep and Deep Publications.

Mukhopadhyay, M. (1998). Asansoler Kotha. In N.D Acharya (Ed.), Asansol er etibrito. Golden Printers.

Najia, K., David, S.B., Grace, F., \& Lalitha, M. (1986). Modifications in food consumption patterns reported by people from India, living in Cincinnati, Ohio. Ecology of Food and Nutrition,
19(1), 11-18.

https://doi.org/10.1080/03670244.1986.99909 42

Peterson, J.C.K. (1910). Burdwan district gazetteer. Bengal Secretariat Book Depot.

Phinney, S.J., Horenczyk, G., Liebkind, K., \& Vedder, P. (2001). Ethnic identity, immigration and well being: An interactional perspective. Journal of Social Issues, 57(3), 493-510. https://doi.org/10.1111/0022-4537.00225

Sanchez, G. (1999). Race, nation, and culture in recent immigration studies. Journal of American Ethnic History, 18(4), 66-84.

www.jstor.org/stable/27502471

Sayegh, L., \& Lasry, J. C. (1993). Immigrants' adaptation in Canada: Assimilation, acculturation, and orthogonal cultural identification. Canadian Psychology, 34(1), 98109. https://doi.org/10.1037/h0078777

Scheffler, S. (2007). Immigration and the significance of culture. Philosophy and Public Affair, 35(2), 93-125.

https://doi.org/10.1057/9780230377

Sengupta, C. (1998). Khoni sramikder arthasamajik abosthar ekal-sekal. In N. D. Acharya (Ed.), Asansol er etibrito. Golden Printers.

\section{Conflict of Interest}

The authors declare that there is no conflict of interest.

\section{Acknowledgements}

The authors express their gratitude to the participants who extended their consent to take part in the primary survey. They are also grateful to the anonymous reviewers and the editor for their valuable comments, suggestion and assistance in improvement of this paper.

\section{About the Authors}

Mukesh Singh has completed M. A. (Geography) in 2016 and M.Phil (Geography) in 2020 from The University of Burdwan. He has two research papers published in various journals of national and international repute. He is keenly interested in the study of migration and culture. 
Professor Giyasuddin Siddique acquired his PhD degree in 1999 from The University of Burdwan. He has nearly 60 research papers published in various esteemed national and international journals, and he has also written six textbooks. Nine scholars have been awarded PhD degree under his supervision. He has more than 30 years' of experience of field-based research on forests, tribal culture, human ecology, social, and environmental problems, river dams, hazard studies, migration, gender issues, human development, quality of life, and culture.

\section{Author Contribution Statement}

Mukesh Singh and Giyasuddin Siddique have mutually delegated the entire work in cooperation starting from conceiving the idea of drafting the final manuscript. Mukesh Singh has conducted the primary survey, prepared the methodology, analysed and processed the data, prepared the table, maps and diagrams and wrote the draft manuscript. Giyassudin Siddique has conceptualised the idea, provided guidance and supervision of the entire research and assisted in interpretation of primary data, editing and reviewing the draft manuscript. 